\title{
Linear Amplification Technique
}

National Cancer Institute

\section{Source}

National Cancer Institute. Linear Amplification Technique. NCI Thesaurus. Code C68778.

Various methods for amplification of nucleic acid sequences by making many copies off the same template. 